\title{
Theoretical basis of optimization of the educational-methodical complex on Literature in the conditions of modern school Informatization
}

\author{
Maria A. Aristova ${ }^{1, *}$, Larisa R. Berdysheva ${ }^{1}$ and Zhanna I. Strizhekurova ${ }^{1}$ \\ ${ }^{1}$ ISED RAE, Center of Philological Education, 105062, Moscow, Russia
}

\begin{abstract}
The article discusses the theoretical basis and new methodological approaches to optimization of the educational-methodical complex in the literature in the conditions of Informatization of the modern school. The authors focus on the basic meaningful components of literary education - the study of the works of classical, modern and foreign literature - linking them in a unified educational system of the reader-student and updating the teaching using modern approaches and relevant tasks for the future..
\end{abstract}

With the national school adopting new educational standards, it is especially important to study the problem and to develop a theoretical foundation regarding the optimization of educational-methodical complex (EMC) on different subjects, including literature. The purpose of optimization is to create the most appropriate conditions for an effective implementation of the National (Federal) Education Standard requirements for learning outcomes in teaching process. While laying emphasis on the leading role of system-activity approach in educational process, the National Education Standard sets the developers of teaching materials a task to form and develop not only subject competences, but also "the competence of learners in the field of information and communication technologies" - ICT [1].

Modern teaching materials for literature includes working with a variety of information resources as a compulsory component, including the Internet, electronic texts, reference books, dictionaries, bibliographic indexes and library catalogues, including the electronic ones. With that said, ICTs should be introduced not only to optimize literature lessons, but also as a means of developing learners' interest in the subject, the acquisition of major meta-subject skills: cultural-orientation skills that help to orient easily in the literary-artistic space, including modern literature, both Russian and foreign, as well as the latest historical and literary-theoretical research and development. In accordance with the requirements of the National Education Standard modern EMC is also intended to the development of learners' project activities that help to achieve personal learning outcomes. System-activity approach to learning, which is stated the basic by the National Education Standard, allows us to build an individual path of learners, which is realized at different stages of the study of classical, modern and foreign literature in the EMC.
The works of Russian classics of the 19th century, which represent the national literary canon, are the basis of EMC on Literature. It is a part of a content component that is most extensively developed both from the theoretical and methodical point of view and it has a long tradition of being studied at school. However, at the same time, the study of classical works is one of the most controversial issues of modern education, which requires a theoretical comprehension with regard to the most optimal implementation of the National Education Standard requirements. On the one hand, a large temporal distance that separates these works from modern pupils creates difficulties in understanding of their specific problems and artistic imagery, even at the level of language units. Such a vocabulary complicates the process of reading and is often a major obstacle to learners' emotional perception of the works in question. EMC on Literature is designed to help overcome these difficulties, for which a variety of technologies can be used: historical and cultural commentary, footnotes, post-text lexical and language development exercises, the inclusion of specifically designed dictionaries, including electronic ones, in the EMC. But with the development of information technology, this range of means can be extended and brought nearer home to the tastes and demands of the learners. The introduction of electronic textbooks in school creates an opportunity to use the technology of hyperlinks that allows pupils to get the necessary information about a particular lexical unit of the text directly in the process of work with it. The scope and boundaries of the information included in the texts of the EMC on Literature may be various, but in any case, this component will contribute greatly to the development of individual learning paths and meta-subject skills of learners.

\footnotetext{
Corresponding author: filolog@instrao.ru
} 
Another problem of studying Russian classics at school is a drop of interest in reading the works of the $19^{\text {th }}$ century. This problem correlates with the overall situation in modern society where there is a loss of the former attitude to reading as a cultural-educational phenomenon. The $21^{\text {st }}$ century school learners often regard fiction of the $19^{\text {th }}$ century as something so far away from their current life that they appeal to it only because of mandatory monitoring and evaluation of knowledge in school. It stands to reason, therefore, that scientists, teaching methods specialists, teachers need to develop a common ground that will overcome these negative trends. The ongoing debates on the Concept of teaching the Russian language and literature, a broad discussion of the modern curriculum for middle school highlight the acute problem of a content component of literary education at school and, especially, the place and role of Russian classics in it. There is an unusually wide range of opinions: from the radical proposals to minimize this material (literally up to several works) to conservative aspirations to preserve everything that once had been included in the school curriculum (and even expand this material). It seems that in order to solve that problem we need to find the optimal balance and theoretically justify the position of the classic literature in the nowadays technologically advanced and accelerated world, which, at first glance, is simply incompatible with measured reading of voluminous novels of the past. Of course, the study of such a difficult problem should be multilateral and complex, but we can already outline some of the ways to optimize the content component of the EMC on Literature.

One of the possible directions is the actualization of problems in the classical works being studied, focusing on those aspects that are lucid and vividly affect the interests of the modern young people.The theoretical positions formulated by scholar-culturologist M.M. Bakhtin are the methodological basis of this approach: "There is neither the first nor the last word and there are no limits for dialogical context (it traces to the infinite past and the infinite future). Even the past meanings, id est. born in the dialogue of the past centuries, can never be stable (finally complete, ultimate) - they will always be changeable (updating) in the process of further, future development of the dialogue" [2]. This very dialogical communication with the author modern learners should try and join despite being separated by ages.

Here is a very typical example related to the study of one of the most significant works of the "golden age" in Russian literature - A.S. Pushkin's novel "Eugene Onegin". Following the classic criticism of V.G. Belinsky, the main character is traditionally characterized and, therefore, analyzed today as "smart unnecessariness" and "superfluous man". Of course, modern literary interpretations of the novel allow us to analyze the character and the work more deeply and comprehensively, without an ideological bias, but there are still the usual stereotypes in school. That being said, it is undoubtedly difficult to imagine ninth-graders being really passionate about the characterization of Onegin as the "superfluous man". The most diligent learners will "deduct" the relevant information from a variety of fundamental studies on this work, while others - will simply "download" the material for an answer from the Internet. Student-centered education, which the National Education Standard strives for, preclude such a question. It is another case, if the EMC on Literature will give the opportunity to organize a discussion on how the "golden youth" is living - be it the nineteenth or twenty-first century. After all, only the decorations have changed, and the questions about what effects this empty, though brilliant, life with a variety of entertainment has on a person, even such an unusual one as Onegin, is no less relevant today. Let Pushkin's main character ride in a luxurious carriage, and not in the "Bentley", while heading to the high society ball, and not to the luxury club, the problem of purpose and meaning of life, which is not occupied with real work that can fulfill the potential of an individual, is quite present-day.

However, it is also important to avoid the vulgar and simplistic "modernization" of the classics to which all sorts of interpretations of the $19^{\text {th }}$ century's works are inclined. For the purposes of literary education at school, this trend is especially dangerous: we shall once again emphasize - the study of literature is based on the ability to enter into a dialogue with the author, and not to impose some kind of "meaning" not inherent in the work. We should not forget that the task of forming and developing the ability of self-interpretation of the work being studied is defined by the system-activity approach and requirements for personal and meta-subject learning outcomes. It is therefore possible to offer another way of optimizing the EMC on Literature: incorporation of exercises aimed at a comparative analysis of the studied work of Russian classics and its interpretation by means of other fine arts. The material for such a comparison can be movies, theater, music, painting, drawing, etc. It is important to define the selection criteria and the way of including this aspect in the EMC, however, the significant educational-pedagogical potential is already obvious.

Suffice to recall the wonderful socio-cultural phenomenon, when a new adaptation of the novel "The Idiot" by F.M. Dostoevsky came out on TV screens in 2003 and caused an unprecedented rise of interest in reading the novel itself among various age and social groups. This example clearly shows that the impact of the modern information space on a person, including a school pupil, can be tremendous. Sore subject of the limited study time seems insignificant in this respect: children and young people follow brand-new films with great interest; viewing of the films may well be organized as an independent extracurricular activity. The task of the teacher in this case is to organize a discussion or a debate, the subject of which correlates with the topics and the directions of studying a literary text specified in the EMC. It is possible to suggest writing reviews as written assignments, or preparing $a$ team project. In any case, such work will not only be focused on achieving substantive results, but also help pupils to identify the individual path of their further development -as a thoughtful skilled reader, with the ability to navigate in today's cultural and information space, and seeking to expand their cultural horizons. 
Introduction of the new the National Education Standard based on the system-activity approach brings with it a number of significant changes in the composition, structure, content and functions of the EMC on Literature. The nature of these changes, their orientation, dynamics, scale and perspective will serve as a prerequisite for the development of new literary programs appropriate to the National Education Standard. Of course, the place and nature of the study of modern literature must be defined in them. The existing curricula and textbooks in literature do not pay enough attention to modern fiction. Most often, books written 30-40 years ago are offered to get pupils acquainted with the contemporary literature. Meanwhile, over the past few decades, there were written a lot of worthy books of contemporary writers about teenagers and for teenagers. Modern literature helps develop emotional sphere of perception of the text. Teenagers are more interested in reading books written in clear and accessible language, they are interested in analyzing the actions of the heroes of their age, discussing topical modern problems. Interesting and systematic reading of contemporary fiction helps to develop the need for communication with the book throughout their lives.

In recent years there have been many studies regarding the status of reading and new reading practices of modern teenagers. They found changes in the motivation for reading, genre and thematic preferences, reading repertoire and its format (reading in an electronic environment, the use of the Internet, blogging, chat on the web). This makes it possible to rethink the content of the literature course in the modern school and the role of leaders in school reading - authors of EMC, teachers, librarians - in an ever-changing media scene.

Of course, literary schooling needs a navigator of worthy and interesting contemporary works, focused on the best traditions of Russian and world literature, which cultivate the spiritual and moral qualities of the person and shape the aesthetic tastes of modern readers. This list of recommended books of modern literature will promote the development of creative and research abilities of pupils, expanding their readers' horizons and knowledge of contemporary reality.

Acquaintance with modern fiction may favorably affect the development of students' needs in the creative self-expression. Modern books presented in electronic form or posted on the Internet develop pupils' navigational skills and learn them to use new information technologies. Most modern writers have their own websites, which are suitable for distance communication with their readers. This may change the very nature of literature lessons. Along with the traditional questions and tasks at lessons entirely new kinds of tasks may appear: to ask the author a question, analyze the response, leave review of the read book on the site, take part in virtual debates, etc. This joint discussion of the fiction in the electronic environment develops the learners' ability to formulate and argue their opinion, give their own assessment of the facts they have read and the facts of modern life. In addition, the reading of contemporary fiction in electronic format allows the students to play the role of creator of a new text: they can change the text and extend it at their option, choose their own illustrations or musical accompaniment. The systematic study of contemporary books during the lessons of literature opens up new vistas for analyzing the work of modern writers in its artistic dynamics, using biographical and critical materials recommended by the teacher or selected personally to create your own research of contemporary literature.

The study of contemporary fiction in the school curriculum develops the National Education Standard's ideas of promoting the study of literature as a school subject and educating a qualified modern reader: the creative, developing personality. Through the acquaintance with books of contemporary writers, metasubject results are being achieved, including learners' ability to work with information, organize self-work, define the areas of interest and socialize. The use of Internet resources of modern literary texts and new information technology develops skills of project activities and creative independence of learners. The survey of school teachers, discussions during lectures and methodological seminars indicate that the modern literary school education is in need of updated programs, complemented by modern fiction, which is focused on the best traditions of classical literature.

Given the goals of optimization and improvement of EMC on Literature in modern educational environment, there have to be clear understanding of the role and place of foreign literature as a component of its content. Literature, as well as culture, of any selected individual nation have never evolved in isolation and has always been a kind of guide, a link in the communication between people of different countries. The best literary works have always appeared at the juncture of different perspectives, in the debate. "Foreign culture, - wrote M.M. Bakhtin, - is revealed more fully and more deeply only in the eyes of another culture... A sense reveals its depth by meeting with the other, foreign meaning ... We are putting new questions to foreign culture, which it itself did not put, we are looking for answers in it, and foreign culture responds to us, opening its new side, new depths of a sense ... With such a dialogical encounter between two cultures, they do not merge and do not mix, each retains its unity and open integrity, but they are mutually enriching "[2]. Indeed, writers of different eras, analyzing and deciding eternal questions and urgent problems of the time in their own way are in a dialogue with each other in their texts, which creates a discussion ground for readers. The discussion as a pedagogical technique is an important part of the EMC on Literature, which is carried out by means of staging problematic issues and comparing classical and modern, Russian and foreign literature.

Foreign literature has been taught in school for many years. Since the $90^{\text {th }}$ of the previous century, there has been a distinct desire to find the linking elements and compare native and foreign literature in the literature curriculums (programs by V.G. Marantsman, T.G. Brazhe, A.G. Kutuzova, G.I. Belenky, A.I. Knyazhytskyy, etc). For example, in the program by A.G. Kutuzov, the holding of a readers' conference was 
proposed: "The character of Don Juan in the works of Alexander Blok, K. Balmont, V. Bryusov, M. Tsvetaeva.". In the program by V.G. Marantsman such problems were put: "The Age and the life of the soul in the poetry of Anna Akhmatova and in the world literature (Catullus)"; "Development and interpretation of biblical plots and characters in world literature (Mephistopheles in Goethe and Pushkin)". A.I. Knyazhytskyy draws attention to the similarities between the myths of different cultures, there are tasks for comparison: "The heroines of Ostrovsky and Leskov as "Shakespearean characters: "a whirlpool of passion" and the "whirlpool of vices"; "Winners and losers in the tales of E. Hemingway "The Old Man and the Sea" and V. Astafyev "King-fish";"The theme of pride in the development of the character of Eugene Bazarov and Julien Sorel in Stendhal"; The works of Chekhov and Shaw. In the programs by B.A. Lanin, L.Yu. Ustinova parallels between characters are set: "The Heroes in Gogol and Merimee: the national peculiarities and universal character traits"; "Byronic hero type," "Hero-thinker in Russian and world literature"; "Childe Harold - Onegin - Pechorin: a tragedy of outstanding personality" and others.

The significant role of foreign literature in modern EMC consists in developing a broader mindset of learners, which contributes to the understanding of the relationship between events and phenomena, seemingly independent but forming a single whole. This is an important meta-subject skill for modern life, in which a person has to work with a huge flow of diverse information.

The modern school is a society in which subjects of education, which belong to different nationalities, ethnicities and cultures, are interacting. In this regard, the role of teaching and education is growing and the emphasis is laid not only on the attention to national identity, but also on the relationship between cultures and finding general and universal things in them; the formation of personality that is able to appreciate the best examples of world culture. The main condition for optimal study of literature in Russian school is the study of Russian literature as a fastening, cementing and unifying basis of literary education. It is significant that there are opinions frequently expressed stating that it is the Russian literature that "in Russia plays the role of a powerful transmitter of European and world culture" [3].

Taking in consideration the fruitful mutual exchange of different cultures in today's information society, it is advisable to build the content of EMC based on a comparison of foreign literature with Russian, on finding of common themes and issues in fictions, as well as on an understanding of national peculiarities and originality of the author's text. One of the main criteria for the success of education today is the strengthening of the role of the learner in the learning process. The student is no longer an object of study but its subject. A dialogue between all participants of the educational process and a possibility of free expression is becoming an underlying principle of building the lessons of literature. The use of ICT in the lessons opens up new vistas for the study of literature. For example, creating a media library with presentations about the life and work of foreign writers, writing research papers and defending projects on foreign literature with the use of the Internet, visiting virtual museums and creating your own tours and gamequests. The use of Internet resources and other ICTs in the EMC on literature is advisable to build as a system of creative, home, project tasks in order to develop interest in reading and encourage independent literary-artistic activities, as well as the ability to present them (a possibility to publish their poems, prose, etc.). ICTs can help in the preparation and participation in various competitions, Olympiads on the subject. A separate heading of the textbook can be an acquaintance of learners with literary sites, where they can find information about new books, literary museums, literary awards and others.

The human need of sense of self in a complex multicultural world has always been acute and urgent. The modern global society includes a wide variety of cultures, subcultures and lifestyles. At the time, Peter Pilsky, a critic of the Russian "first wave" of emigration, wrote: "Literature is becoming alive cement that is linking universal and national culture with the motherland, the state and the people" [4]. An interlinked study of literature in the conditions of information educational environment gives a sense of belonging to your own roots, national culture and also to join the cultural experience of the whole humanity. We believe that the finding of common criteria for the interconnected learning, development of new teaching methods, interesting forms of oral and written assignments with the use of ICT is the most appropriate and promising approach for modern EMC on literature.

The main purpose of the study of literature in school is to form such traits and abilities as an understanding of the importance of reading for personal development, discovery of the world and awareness of your place in it, the definition of cultural identity, the ability to build a harmonious relationship in the modern society, the skills of intercultural communication. Learners-readers by enriching their native language through reading of the best works of Russian and foreign classics and modern literature learn to use meta-subject and subject skills in their written and oral statements of different kinds and genres. The formation of the concept of the literary correlations gives a new perspective on the development of the reader's perception of the modern learner and allows them to see the integrity of literature as a cultural phenomenon of all humankind.

\section{References}

1. The National (Federal) Education Standard of general education. The Ministry of Education and Science of the Russian Federation. Available online: URL минобрнауки.рф/документы/938 (accessed on: 03.03.2016) [In Rus]

2. M.M. Bahtin, To the methodology of humanities (Moscow, 1979) [In Rus] 
3. M.N. Kuzmin, Modernization of Russia: the problem of the organization of a unified educational space in the conditions of polytechnic (Moscow, 2003) [In Rus]

4. B.A. Lanin, Zh.I. Strizhekurova, Russian Abroad: rediscovery of the classics. Toolkit (Moscow, 2008) [In Rus] 